\title{
The Responses of Female Baboons (Papio cynocephalus ursinus) to Anomalous Social Interactions: Evidence for Causal Reasoning?
}

\author{
Dorothy L. Cheney and Robert M. Seyfarth \\ University of Pennsylvania
}

\author{
Joan B. Silk \\ University of California, Los Angeles
}

\begin{abstract}
Baboons' (Papio cynocephalus ursinus) understanding of cause-effect relations in the context of social interactions was examined through use of a playback experiment. Under natural conditions, dominant female baboons often grunt to more subordinate mothers when interacting with their infants. Mothers occasionally respond to these grunts by uttering submissive fear barks. Subjects were played causally inconsistent call sequences in which a lower ranking female apparently grunted to a higher ranking female, and the higher ranking female apparently responded with fear barks. As a control, subjects heard a sequence made causally consistent by the inclusion of grunts from a 3rd female that was dominant to both of the others. Subjects responded significantly more strongly to the causally inconsistent sequences, suggesting that they recognized the factors that cause 1 individual to give submissive vocalizations to another.
\end{abstract}

Causal reasoning involves the recognition of a functional relation between two events. This relation is invariant and irreversible; if A causes B, B cannot cause A. Philosophers since at least Aristotle have debated the nature of causal reasoning in human thinking. Although the British empiricist David Hume (1739) argued that it is impossible for humans to perceive more than spatial and temporal associations between events, subsequent investigations have shown clearly that humans differentiate between events that are merely contingent and those that occur together because one causes the other. In his classic experiments on humans' perception of causality, Michotte (1946/1963) found that participants perceived two events to be causally related if they occurred in close temporal proximity and shared some "phenomenal integration" that appeared to link them in the participant's mind. Some pairs of stimuli were more likely

Dorothy L. Cheney and Robert M. Seyfarth, Departments of Biology and Psychology, University of Pennsylvania; Joan B. Silk, Department of Anthropology, University of California, Los Angeles.

This research was supported by grants from the National Geographic Society, the Research Foundation of the University of Pennsylvania, the Institute for Research in Cognitive Science at the University of Pennsylvania, and National Institutes of Health Grant HD-29433.

We thank the Office of the President and the Department of Wildlife and National Parks of the Republic of Botswana for permission to conduct research in the Moremi Game Reserve. We are grateful to W. Hamilton, R. Boyd, Mongabe Kgosiekae, and Mokopi Mokopi for logistical support and to M. Cords, P. Glimcher, M. Hauser, and E. Visalberghi for comments.

Correspondence concerning this article should be addressed to Dorothy L. Cheney, Department of Biology, University of Pennsylvania, Philadelphia, Pennsylvania 19104. Electronic mail may be sent via Internet to Cheney@cattell.psych.upenn.edu. than others to produce an impression of causality, although participants often found it difficult to specify precisely why this was so. Subsequent research has shown that even infants and very young children make use of causal reasoning in their evaluations of mechanical forces, biological function, and mental states. Interestingly, however, there may be important qualitative differences in their causal reasoning in different domains (see, e.g., Gelman \& Spelke, 1981; Keil, 1990, 1991; Leslie, 1984; Leslie \& Keeble, 1987; Perner, 1991; Spelke, 1990; Wellman \& Gelman, 1992).

Little is known about the extent or even existence of causal reasoning in animals (see discussion by Fales \& Wasserman, 1992). Some of the earliest attempts to investigate the perception of causality in nonhuman primates were carried out on chimpanzees (Pan troglodytes). Premack (1976; see also Premack \& Premack, 1994), for example, presented a number of language-trained chimpanzees with a choice of alternative agents to complete a sequence of actions and found that they chose the correct agent with a high degree of accuracy. The numerous examples of tool use by free-ranging chimpanzees also suggest some understanding of cause and effect (Boesch, 1991; Boesch \& Boesch, 1983; Goodall, 1970; Kohler, 1927/1959). Chimpanzees' understanding of cause-effect relations may even extend to mental states. Although most of the data are anecdotal, there is suggestive evidence that chimpanzees recognize that other individuals have beliefs and that beliefs can influence behavior (Povinelli, Nelson, \& Boysen, 1990; Premack \& Woodruff, 1978; Whiten, 1991; Whiten \& Byrne, 1988).

There is little evidence that monkeys use causal reasoning in similar contexts. Experiments on imitation and tool use in captive capuchin monkeys (Cebus apella), for example, suggest that subjects have no understanding of the causal 
relations that link objects, actions, and outcomes (Visalberghi \& Fragaszy, 1990; Visalberghi \& Limongelli, 1994; Visalberghi \& Trinca, 1989). Similarly, numerous observations and a few experiments have suggested that monkeys do not understand the causal relation between beliefs and behavior. For example, they do not selectively inform ignorant animals of danger or food, nor do they imitate or teach (reviewed in Cheney \& Seyfarth, 1990). The basis for this ignorance, however, is not understood. Although the apparent lack of causal reasoning in some contexts might stem from a general failure to understand causal relations, monkeys' poor performance might also be restricted to particular domains. It is possible, for example, that a monkey that fails to recognize that beliefs can influence behavior might nevertheless recognize that a stick pushed against a piece of fruit causes the fruit to move.

There is currently widespread speculation that primate intelligence is specifically adapted to solve social problems (Byrne \& Wihiten, 1988; Cheney \& Seyfarth, 1985; Humphrey, 1976; Jolly, 1966). If this hypothesis has any validity, we might predict that evidence of causal reasoning in monkeys would be more evident in the domain of social behavior than, for example, in interactions with food or other physical objects. In fact, when interacting with each other, monkeys often behave as if they do have some understanding of cause-effect relations. A juvenile monkey that avoids a fight with the daughter of a high-ranking female, for example, acts as if she recognizes that a fight will cause that individual's mother to intervene. Her behavior might also, however, be the result of a learned contingency: Fighting with a particular individual has become associated with a subsequent threat by a high-ranking female. It is difficult to find examples of social behavior in free-ranging monkeys that can be explained only in terms of causal reasoning.

In this article, we describe an experiment designed to investigate monkeys' understanding of cause-effect relations in the context of social interactions. In the experiment, we examined whether adult female baboons (Papio cynocephalus ursinus) recognize the factors that cause one individual to give submissive vocalization to another.

Like many other species of Old World monkeys, female baboons can be ranked in stable, linear dominance hierarchies (Hausfater, Altmann, \& Altmann, 1982; Seyfarth, 1976; Smuts \& Nicolson, 1989). Normally, if a dominant female approaches a more subordinate individual, the subordinate is supplanted and moves away. If, however, the dominant female vocalizes to the subordinate using a lowamplitude, low-pitched, tonal grunt, the subordinate is less likely to move away, and the two females may groom or interact in some other friendly way (Cheney, Seyfarth, \& Silk, in press).

Infant baboons are highly attractive to other females (Altmann, 1980; Seyfarth, 1976). In a typical interaction involving a dominant female and a subordinate mother, the dominant female approaches the subordinate mother, grunts repeatedly to her, and then attempts to handle her baby. Occasionally, a subordinate mother will utter one or several short, sharp "fear barks" when the dominant female at- tempts to interact with her. Females give fear barks only to higher ranking individuals; in $605 \mathrm{hr}$ of focal animal sampling on 19 adult females, females never uttered a fear bark when interacting with individuals of lower rank than themselves.

There is no obligatory order to the temporal pattern of grunts and fear barks (see below). The majority of grunts occur in the absence of fear barks. Often grunts and fear barks are given by the same individual, as, for example, when a female approaches a higher ranking mother to look at her infant. Subordinate females may also give fear barks in the absence of grunts. Similarly, there is no obligatory temporal relationship between grunts and fear barks when two different females are giving the calls; a subordinate female may give a fear bark before the dominant female grunts, or a dominant female may continue to grunt for several seconds after the subordinate female has finished uttering fear barks. Grunts, therefore, can both precede and follow fear barks. However, when one female grunts and another gives a fear bark, there is an obligatory relationship between the participants' relative ranks: Grunts from a higher ranking female can evoke fear barks from a lower ranking female, but the reverse can never occur. It is knowledge of this obligatory relationship that the experiment was designed to address.

In the experiment, we tested whether baboon females recognize that only a more dominant animal can cause another individual to give a fear bark. Specifically, we constructed anomalous sequences of calls in which a subordinate female appeared to give repeated grunts in the context of handling a more dominant mother's infant, followed by fear barks on the part of the dominant mother. We reasoned that, if subjects recognized the causal inconsistency in this sequence, they should respond more strongly to it than to a similar sequence of calls that showed no causal inconsistency.

\section{Rationale for the Experimental Design}

In designing this experiment, we made a number of assumptions and predictions, drawing on the results of earlier playback experiments involving many species of old World monkeys. First, we assumed that free-ranging baboons could recognize the calls of individuals within their group. This assumption seemed warranted given the many playback studies that have already documented individual recognition by voice in nonhuman primates (e.g., baboons: Cheney et al., in press; Palombit, 1996; vervet monkeys [Cercopithecus aethiops]: Cheney \& Seyfarth, 1980, 1982a, 1982b, 1988; rhesus macaques [Macaca mulatta]: Hansen, 1976; S. Gouzoules, Gouzoules, \& Marler, 1984; pigtail macaques [Macaca nemestrina]: H. Gouzoules \& Gouzoules, 1989; mangabeys [Cercocebus albigena]: Waser, 1977; squirrel monkeys [Saimiri sciureus]: Kaplan, Winship-Ball, \& Sim, 1978; titi monkeys [Callicebus moloch]: Robinson, 1981; gibbons [Hylobates muelleri]: Mitani, 1985).

Second, we assumed that subjects could recognize the 
relative dominance ranks of other adult females in their group. As with our assumption about individual recognition, this assumption seemed warranted on the basis of prior research on stumptail macaques (Macaca arctoides; $\mathrm{H}$. Gouzoules, 1975), baboons (Scott, 1984; Seyfarth, 1976), and vervet monkeys (Cheney \& Seyfarth, 1990; Seyfarth, 1980).

Third, we predicted that subjects would respond to both types of call sequences by looking in the direction of the speaker. We made this assumption for two reasons. First, field observations indicated that baboons typically respond to naturally occurring grunts and fear barks by either ignoring them or orienting briefly toward them (see below). Second, in virtually all previous studies in which baboons or other monkeys have been played within-group vocalizations, subjects have typically responded by looking in the direction of the speaker (e.g., vervet monkey screams, grunts, and intergroup calls: Cheney \& Seyfarth, 1980, 1982a, 1988; Hauser, 1986; rhesus macaque screams: S. Gouzoules et al., 1984; baboon screams: Cheney et al., in press; Palombit, 1995). To date, playbacks of only two types of calls have consistently elicited responses other than orientation toward the speaker: predator alarm calls (e.g., Seyfarth, Cheney, \& Marler, 1980) and calls associated with territorial defense (e.g., Mitani, 1985; Robinson, 1981; Waser, 1977).

Fourth, we predicted that subjects would look in the direction of the speaker for a longer duration when hearing the causally inconsistent sequence than when hearing the consistent control series. This prediction was based on results from previous studies that presented monkeys with anomalous calls. In one study of vervet monkeys, for example, subjects were played the calls of monkeys belonging to neighboring groups, either from those monkeys' actual territories or from an inappropriate territory. Subjects oriented toward the source of the calls for a longer duration when the calls were played from the anomalous territory (Cheney \& Seyfarth, 1982b; see also Brooks \& Falls, 1975, for a similar experiment on white-crowned sparrows Zonotrichia leucophys).

Habituation-dishabituation experiments offer another example of experiments in which subjects responded to novel or anomalous calls by looking toward the speaker for a longer duration of time. For example, vervet monkeys that have habituated (i.e., ceased to look toward the speaker) after the repeated presentation of the same individual's intergroup call will dishabituate (i.e., look toward the speaker for a significantly longer duration) if they then hear a different individual's intergroup call (Cheney \& Seyfarth, 1988). The change in the identity of the signaler is, apparently, sufficiently novel or inconsistent to elicit the stronger response (see also Seyfarth \& Cheney, 1990, for similar experiments using alarm calls with different referents).

Given these prior results, we assumed that, in this series of experiments, subjects would recognize the identities of individual callers and their relative dominance ranks, would look toward the speaker on hearing grunts and fear barks, and would respond more strongly-by looking toward the speaker for longer durations- to the causally inconsistent series of calls than to a similar series of calls that was causally consistent.

\section{Method}

\section{Study Site and Subjects}

Subjects were part of a group of approximately 70 baboons living in the Okavango Delta, Botswana. The group has been observed continuously since 1977 by Hamilton and colleagues (e.g., Bulger \& Hamilton, 1988; Hamilton \& Bulger, 1992), and maternal relationships for all natal animals are known. All animals are fully habituated to human observers on foot. Experiments were conducted over a 4-month period as part of a year-long study of communication and social behavior. Subjects were drawn from a sample of 19 adult females that were also the focus of the observational study.

\section{Playback Stimuli}

The causally inconsistent sequence of calls consisted of three to four grunts originally recorded from a middle- or low-ranking female in the context of handling an even lower ranking female's infant, followed by two to three submissive fear barks originally recorded from a more dominant mother. (The number of grunts and fear barks played in any given sequence was typical of normally occurring sequences). For example, in a group in which Female $\mathrm{A}$ was the highest ranking and Female $\mathrm{S}$ was the lowest ranking, the inconsistent sequence might consist of Female F's grunts followed by Female B's fear bark. The anomaly occurred because the grunting female was subordinate to the mother and would never ordinarily cause the mother to give fear barks.

These sequences presented subjects with an unusual combination of calls. As a result, subjects might have responded strongly to the playback tapes not because they recognized a causal inconsistency but simply because this combination of calls was novel. To avoid this confound, we designed a series of control experiments in which the grunts of a third female were added to the sequence of calls. This female was dominant to the mother giving the fear barks. For example, if the inconsistent sequence was composed of Female F's grunts followed by Female B's fear bark, the corresponding consistent sequence might begin with Female A's grunts, followed by Female F's grunts, and end with Female B's fear bark. Thus, although the anomalous calls were retained in the playback tape, the addition of the third female's calls made the sequence causally logical.

If baboons recognized that this second series of calls was causally consistent, they should have responded less strongly to playbacks of them than to playbacks of the inconsistent series. By contrast, if they made no assessment of the relation between grunts, fear barks, and the relative ranks of the females producing them (e.g., if they treated grunts and fear barks as occurring together simple by chance), they should have responded equally strongly to both the causally inconsistent and the causally consistent sequences.

The sample of fear barks was drawn from all mothers with currently suckling infants from whom we had high quality tape recordings. Grunts were chosen on the basis of sound quality and the grunting female's dominance rank relative to the mother. Nine different pairs of control and test sequences were constructed, using the grunts of 11 females and the fear barks of 5 mothers (Table 1). In half of the control sequences, the call of the most dominant female occurred first in the sequence; in the other half, 
Table 1

Combinations of Calls Used in the Playback Sequences

\begin{tabular}{|c|c|c|c|c|c|}
\hline \multicolumn{4}{|c|}{ Inconsistent sequence } & \multirow{2}{*}{\multicolumn{2}{|c|}{$\begin{array}{c}\begin{array}{c}\text { Consistent } \\
\text { sequence }\end{array} \\
\begin{array}{c}\text { Additional } \\
\text { grunting female }\end{array}\end{array}$}} \\
\hline \multicolumn{2}{|c|}{ Grunting female } & \multicolumn{2}{|c|}{$\begin{array}{l}\text { Fear-barking } \\
\text { mother }\end{array}$} & & \\
\hline$\overline{\text { Name }}$ & Rank & Name & $\overline{\text { Rank }}$ & Name & Rank \\
\hline $\mathrm{SH}$ & 7 & SY & 2 & ST & 1 \\
\hline SS & 8 & SY & 2 & ST & 1 \\
\hline $\mathrm{LE}$ & 11 & WR & 9 & SY & 2 \\
\hline NI & 12 & WR & 9 & $\mathrm{BT}$ & 3 \\
\hline MR & 15 & NN & 13 & LE & 11 \\
\hline $\mathrm{AL}$ & 16 & HN & 6 & ST & 1 \\
\hline $\mathrm{OL}$ & 17 & $\mathrm{AL}$ & 16 & WR & 9 \\
\hline $\mathrm{CD}$ & 19 & $\mathrm{HN}$ & 6 & SY & 2 \\
\hline $\mathrm{CD}$ & 19 & $\mathrm{HN}$ & 6 & BT & $\overline{3}$ \\
\hline
\end{tabular}

Note. In the causally inconsistent sequences, a low-ranking female's grunt was paired with a higher ranking female's fear bark. In the causally consistent sequences, the grunt of a female that ranked higher than either of the two original females was added to the sequence. Initials indicate each female's name.

her call appeared second. The calls of closely related females (mothers, daughter, and sisters) were not used in the same sequence.

\section{Procedure}

Subjects were 18 different adult females, all of whom were at least 6 years of age. Each female heard one causally consistent and one causally inconsistent sequence of calls. Three females appeared twice as subjects, but in each case they heard a different combination of calls in different paired trials. In 8 of the 21 paired trials, the subject was higher ranking than the female whose fear bark was played; in the other 13 trials, the subject was lower ranking. The order in which subjects were played the two call sequence types was systematically varied. Trials involving the same female were always separated by at least $24 \mathrm{hr}$.

Calls were played to females from a concealed Nagra $\mathrm{DH}$ loudspeaker at a mean distance of approximately $5 \mathrm{~m}$. Because the group was often dispersed through thick brush over distances of up to $1 \mathrm{~km}$, it was relatively easy to ensure that trials were conducted only when subjects were out of sight of the two or three individuals whose calls were being played. We made no attempt to control the context in which calls were played, reasoning that females would be sensitive to the anomalous calls regardless of whether they were feeding, sitting, or grooming another individual.

In all trials, subjects were videotaped. Filming commenced $10 \mathrm{~s}$ before the onset of the call and continued for another $10 \mathrm{~s}$ following the last fear bark. Responses were measured in terms of the duration that subjects looked toward the speaker following the onset of the fear barks minus the duration of time that they looked toward the speaker in the seconds before the calls were played.

\section{Observational Data}

To verify that baboons responded to the playback stimuli in the same way that they responded to naturally occurring calls, we also gathered baseline data on females' responses to vocalizations that occurred during real social interactions. These data were gathered opportunistically during a $1 \mathrm{hr}$ period each day for 3 months.
Whenever 1 or 2 females vocalized during a social interaction, we noted the type of response it evoked in others and the duration of this response. Potential listeners were defined as any females sitting within $5 \mathrm{~m}$ of the interaction that were not already oriented toward the interaction when it began. The duration of listeners' responses was timed with a stopwatch. Although data were gathered opportunistically, all females appeared as listeners at least 11 times. There were no individual differences among females in either the type or the duration of response.

\section{Results}

When hearing naturally occurring grunts, fear barks, or combinations of these two calls, female baboons who were out of sight of the interaction responded by either orienting briefly toward the interaction or ignoring the calls entirely (Table 2). Orientation was the only response elicited by these calls.

Subjects responded equally weakly to playbacks of the causally consistent sequences of calls (Figure 1). Subjects hearing these control sequences either ignored the calls or looked briefly in the direction of the speaker. The mean duration of subjects' responses to playbacks of the causally consistent control sequences was $0.6 \mathrm{~s}(S D=0.8 \mathrm{~s})$. Their responses to naturally occurring calls were of a similar short duration (Table 2).

In contrast, subjects responded significantly more strongly when played the causally inconsistent sequences of calls. In 15 of 21 paired trials, females looked toward the speaker for a longer duration when played the inconsistent sequences than when played the control sequences. In 4 cases, they looked for a shorter duration, and in 2 cases, their responses were tied (Figure 1, one-tailed Wilcoxon matched-pairs signed-ranks test, $T=26.5, p<.01$ ). In a more conservative analysis, we combined the scores of the 3 females that appeared twice as subjects to obtain a mean score for each individual. Results remained the same, $(N=$ 18 , two ties, $T=17.5, p<.01$ ).

Table 2

Duration That Females Oriented Toward Naturally Occurring Calls

\begin{tabular}{|c|c|c|c|}
\hline \multirow[b]{2}{*}{ Call sequence type } & \multirow{2}{*}{$\begin{array}{c}\text { No. } \\
\text { observed }\end{array}$} & \multicolumn{2}{|c|}{$\begin{array}{l}\text { Duration of orienting } \\
\text { toward the call } \\
\text { (in seconds) }\end{array}$} \\
\hline & & $M$ & $S D$ \\
\hline A grunts to $B$ & 104 & 0.3 & 1.1 \\
\hline $\mathrm{B}$ grunts to $\mathrm{A}$ & 125 & 0.2 & 0.9 \\
\hline $\mathrm{B}$ fear barks to A & 21 & 0.6 & 1.1 \\
\hline$B$ grunts and fear barks to $A$ & 42 & 0.5 & 1.2 \\
\hline$A$ and $B$ exchange grunts & 33 & 0.4 & 1.0 \\
\hline A grunts, B fear barks & 25 & 0.5 & 1.1 \\
\hline B fear barks, A grunts & 3 & 0 & 0 \\
\hline
\end{tabular}

Note. Data were gathered opportunistically over a 3-month period by timing the orienting responses of potential listeners to calling females. Potential listeners were defined as any females sitting within $5 \mathrm{~m}$ of the interaction that were not already oriented toward the interaction when it began. $A$ and $B$ refer to different females, where $A$ is dominant to $B$. 


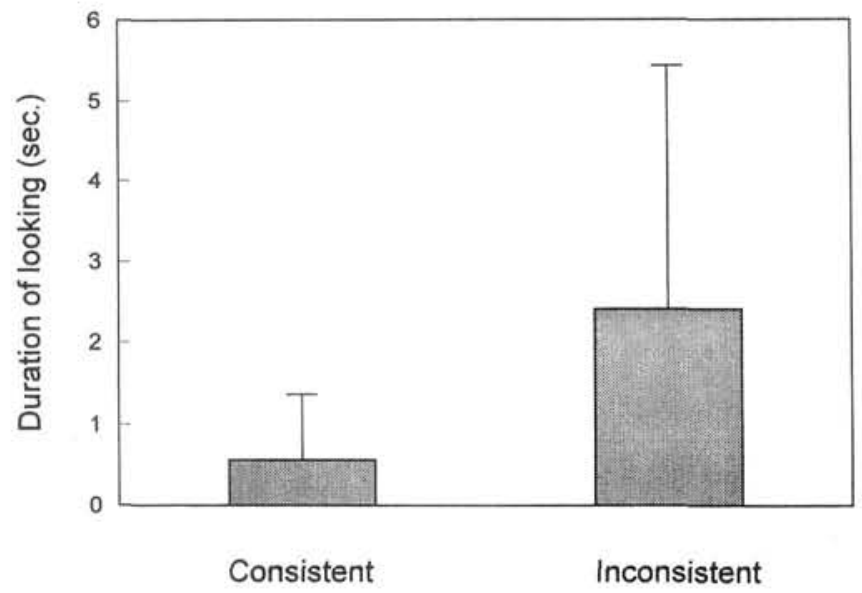

Figure 1. The mean duration of subjects' responses to playbacks of causally inconsistent and causally consistent call sequences. Histograms show means and standard deviations for 21 subjects in each of the two conditions.

There was no correlation between the strength of subjects' responses and the disparity in the relative ranks of the grunting and fear-barking females $\left(N=21, r_{s}=.018\right)$. Evidently, even a small apparent change in the female dominance hierarchy was sufficient to cause subjects to orient toward the test sequence. The ranks of subjects relative to the females giving fear barks also did not affect response duration. Subjects that were higher ranking than the fear-barking female responded as strongly as subjects that were lower ranking.

For at least three reasons it seems unlikely that subjects responded more strongly to the test sequences simply because they were more novel than the control sequences. First, novel combinations of calls were retained in the causally consistent control sequences. Second, even under natural conditions the sample of control sequences almost never occurred. In $605 \mathrm{hr}$ of focal animal sampling on adult females, none of the triadic combinations of calls used in the control sequences ever occurred naturally. The causally consistent control sequences were, therefore, probably as novel as the causally inconsistent test sequences.

Third, even sequences involving only two of the three control calls-the most dominant female's grunt and the subordinate mother's fear bark-occurred at low rates. Five different dominant females' grunts were used in control trials. When we examined all the occasions when 1 of these females had grunted to 1 of the 5 mothers whose calls were used in the experiments, we found only five instances in which 1 of these female's grunts had been followed by 1 of these mother's fear barks. Indeed, on average, this combination of calls occurred only once in every $28.8 \mathrm{hr}$ of focal animal sampling. In their social interactions, therefore, subjects rarely heard even a portion of the control sequences.

\section{Discussion}

In Michotte's (1946/1963) classic experiments on the perception of causality, human participants were able to report whether a complex series of events, like one ball rolling from left to right, colliding with another, and moving the other to the right, seemed to be causally related or not. Documenting a sensitivity to cause-effect relations in nonhuman species is much more difficult. Because subjects cannot report why they respond differently to two different stimuli, there are inevitably many alternative explanations for their behavior. Faced with this problem, scientists studying the perception of cause-effect relations in animals or preverbal children (see previous references) have typically presented their subjects with a problem or test that, if it were faced by adult humans, could only be solved using causal reasoning. Then, if subjects performed successfully, the investigators have tried to eliminate any alternative explanations for their behavior. In this respect, this study is no different from those that have preceded it.

When free-ranging baboons hear grunts and fear barks in sequence, they respond as if they recognize that these calls do not occur together simply by chance. Some combinations of calls elicit a strong response; others do not. There are a number of possible explanations for the baboons' behavior, at least some of which can probably be eliminated.

It is unlikely that females responded more strongly to the causally inconsistent sequences because these sequences were, for some reason, acoustically more salient. If anything, the causally consistent sequences were probably more salient because they contained more vocalizations and were of longer duration. Causally consistent sequences, however, received less attention than the shorter, causally inconsistent sequences. Similarly, the baboons' behavior cannot be explained in terms of a stronger response to novel sequences because both the control and experimental sequences were novel. Control trials were made logically consistent, but no less unique, by the inclusion of a more dominant female's grunts. Finally, results did not occur because subjects simply responded more strongly to the grunts or fear barks of an animal that was higher ranking than themselves, or because the strength of their response depended on the disparity between the dominance ranks of the animals whose grunts and fear barks they were played.

With these alternatives eliminated, the simplest explanation for the results described here is that female baboons in some way recognize that fear barks occur in the context of interactions with more dominant individuals. As a result, they respond strongly if the relative ranks of the grunting and fear-barking females are reversed. Note, however, that this seemingly simple explanation demands that baboons integrate at least four sorts of information when attending to call sequences. First, they must recognize other individuals' calls. Second, they must recognize other females' relative dominance ranks. Third, they must recognize that fear barks can only be evoked by more dominant animals. Fourth, when grunts and fear barks are temporally juxtaposed, they must assume that the fear barks were elicited (or caused) by the individual giving the grunts.

Fear barks are never given to lower ranking females. When listeners hear a low-ranking female's grunt followed by a higher ranking female's fear bark, they respond strongly because this sequence suggests a reversal in the 
females' relative ranks. The listeners' strong responses, however, depend not only on knowledge of other females' dominance ranks but also on the inference that one female's grunt has acted to bring about the other's fear bark. In other words, the females' behavior cannot be explained without assuming that baboons impute some sort of causal relation (or something like what we call a causal relation in humans; see below) between grunts and fear barks.

The stimuli used in the playback experiments were not themselves anomalous. Under natural conditions, when a dominant female grunts and a subordinate female fear barks, listeners either ignore the interaction or orient toward it for a short duration. Their responses are typically weaker, however, than the responses of subjects that heard the anomalous grunt and fear bark combination. Similarly, under natural conditions, it is not unusual for a subordinate female's grunt to precede a call from a higher ranking female. When this occurs, however, the higher ranking female's call is always a grunt and never a fear bark. Nor is a fear bark from a high-ranking female by itself unusual. High-ranking females do give fear barks but only to those of even higher rank. Finally, as the control trials demonstrate, a low-ranking female's grunt can occur in close temporal association with a higher ranking female's fear bark without appearing to be anomalous, but only if these calls are combined with the grunt of an even higher ranking female. It was, then, not the stimuli themselves but the presumed causal relation among caller identity, caller rank, and call type that made certain sequences anomalous.

As a final alternative, it might be argued that baboons simply recognize the "rules" for giving different sorts of vocalizations: Grunts can be given either up or down the dominance hierarchy, but fear barks are only given to higher ranking individuals. The design of the causally consistent control trials, however, makes this explanation unlikely. In the control sequences, grunts from a low-ranking female, $F$, were paired with fear barks from a higher ranking female, C. This anomaly did not produce a strong reaction, however, because the calls were accompanied by grunts from an even higher ranking female, $\mathrm{A}$. The failure to respond to such an anomaly could only have occurred if subjects somehow perceived that A's grunts, and not F's, were the reason for C's fear bark.

To say that female baboons recognize the causal relation between a dominant female's grunt and a subordinate female's fear bark implies nothing about the processes, cognitive or otherwise, that might underlie causal judgments. There is no doubt that even very simple organisms are capable of learning to recognize cause-effect relations, in the sense that they recognize a contingency between two associated events (reviewed in Macintosh, 1974; see also Fales \& Wasserman, 1992; Premack \& Premack, 1994). What is not known, and what our experiment cannot address, is whether baboons' causal reasoning is of the mechanistic sort first proposed by Hume and later formalized in models of classical conditioning (e.g., the Rescorla-Wagner model, 1972) or of a more inductive, hypothesis-driven sort (e.g., Bayesian reasoning: Fales \& Wasserman, 1992). Indeed, these two extremes are difficult to distinguish even in humans. There is, for instance, substantial evidence that, in their everyday reasoning about causal relations, humans apply mechanistic models based on contingency more often than not, simply because this rule of thumb generally works.

The results reported here represent a first step in the investigation of monkeys' perception of cause-effect relations in what might be called the social domain. In contrast, most previous studies of the perception of cause-effect relations in primates have focused on these animals' interactions with objects: for example, their use of tools (e.g., Visalberghi \& Limongelli, 1994), or their ability to use objects to solve a variety of problems (e.g., Kohler, 1925/ 1959; Premack, 1976). Although relatively few primates use tools, however, virtually all confront in their daily lives a variety of social problems whose solution may require an understanding of cause-effect relations (Humphrey, 1976; Jolly, 1966). At the very least, further investigation into the perception of causality in the social domain seems warranted.

Outside the social domain, evidence for the perception of cause-effect relations in monkeys is mixed. Despite an apparently sophisticated knowledge of their companions' relative ranks and close associates, free-ranging vervet monkeys seem not to recognize the causal relation between pythons and the tracks they produce or leopards and the carcasses they put in trees (Cheney \& Seyfarth, 1985, 1990). These differences might be related to a fundamental discrepancy in the way that vervet monkeys respond to events in the context of social interactions as opposed to similar events in the external world (Visalberghi, 1992). They could also, however, be due to a range of other factors (Cheney \& Seyfarth, 1993). Similarly, in tests that require subjects to push a piece of food out of a tube using a stick, capuchin monkeys fail to understand the causal relations involved (Visalberghi \& Limongelli, 1994). Using trial-and-error methods, however, these same monkeys do eventually learn to use sticks to remove items from plastic tubes (Visalberghi \& Trinca, 1989; see also Beck, 1980, and Tokida, Tanaka, Takefushi, \& Hagiwara, 1994, for similar tool-using abilities in captive baboons and Japanese macaques [Macaca fuscata]). Several laboratory studies have shown that monkeys can learn to use joy sticks to track spatially discontinuous events on a computer screen (Andrews, 1993; Rumbaugh, Richardson, Washburn, \& Savage-Rumbaugh, 1989; Washburn, Hopkins, \& Rumbaugh, 1989), a behavior that is at least consistent with an understanding of the causal properties of motion in inanimate objects. There is some evidence that particular areas in the temporal cortex of rhesus macaques are more responsive to causally related movement patterns than to movements that are merely contiguous (Perret, Harries, Mistlin, \& Chitty, 1990). Whether or not the same or other areas in the brain are also sensitive to causal events in social interactions is not yet known.

In summary, female baboons act as if they apply causal reasoning to the interactions and relationships of others, recognizing that a given female's submissive fear bark can be evoked by interactions with some sorts of individuals but not by others. Females respond strongly to an interaction that appears to be causally inconsistent and to violate their 
knowledge of each others' relative ranks. If, however, the interaction is made logically consistent by the inclusion of an even more dominant female's call, they respond less strongly to it. Although these results are consistent with an explanation based on causal reasoning, no one study can ever hope to provide definitive evidence for the presence or absence of causal reasoning, in animals or in humans. Even in the human case, where an understanding of the mechanisms that underlie behavior is much easier to obtain, it remains both philosophically and empirically difficult to define the critical components of causal reasoning in different domains.

\section{References}

Altmann, J. (1980). Baboon mothers and infants, Cambridge, MA: Harvard University Press.

Andrews, M. W. (1993). Video task paradigm extended to Saimiri. Perceptual and Motor Skills, 76, 183-191.

Beck, B. (1980). Animal tool behavior: The use and manufacture of tools by animals. New York: Garland.

Boesch, C. (1991). Teaching in wild chimpanzees. Animal Behaviour, 41, 530-532.

Boesch, C., \& Boesch, H. (1983). Optimisation of nut-cracking with natural hammers by wild chimpanzees. Behaviour, 83 , 265-286.

Brooks, R. J., \& Falls, J. B. (1975). Individual recognition by song in white-crowned sparrows. III. Song features used in individual recognition. Canadian Journal of Zoology, 53, 1749-1761.

Bulger, J., \& Hamilton, W. J. (1988). Inbreeding and reproductive success in a natural chacma baboon, Papio cynocephalus ursinus, population. Animal Behaviour, 36, 574-578.

Byrne, R., \& Whiten, A., (Eds.) (1988). Machiavellian intelligence: Social expertise and the evolution of intellect in monkeys, apes, and humans. Oxford, England: Oxford University Press.

Cheney, D. L., \& Seyfarth, R. M. (1980). Vocal recognition in free-ranging vervet monkeys. Animal Behaviour, 28, 362-367.

Cheney, D. L., \& Seyfarth, R. M. (1982a). How vervet monkeys perceive their grunts: Field playback experiments. Animal Behaviour, 30, 739-751.

Cheney, D. L., \& Seyfarth, R. M. (1982b). Recognition of individuals within and between groups of free-ranging vervet monkeys. American Zoologist, 22, 519-529.

Cheney, D. L., \& Seyfarth, R. M. (1985). Social and non-social knowledge in vervet monkeys. In L. Weiskrantz (Ed.), Animal intelligence (pp. 187-201). Oxford, England: Clarendon Press.

Cheney, D. L., \& Seyfarth, R. M. (1988). Assessment of meaning and the detection of unreliable signals by vervet monkeys. Animal Behaviour, 36, 477-486.

Cheney, D. L., \& Seyfarth, R. M. (1990). How monkeys see the world: Inside the mind of another species. Chicago: University of Chicago Press.

Cheney, D. L., \& Seyfarth, R. M. (1993). Dogs that don't bark in the night: How to investigate the lack of a domain of expertise? PSA 1992, 2, 92-109.

Cheney, D. L., Seyfarth, R. M., \& Silk, J. B. (in press). The role of grunts in reconciling opponents and facilitating interactions among adult female baboons. Animal Behaviour.

Fales, E., \& Wasserman, E. A. (1992). Causal knowledge: What can psychology teach pholosophers? Journal of Mind and Behavior, 13, 1-28.

Gelman, R., \& Spelke, E. (1981). The development of thoughts about animate and inanimate objects. In J. H. Flavell \& L. Ross
(Eds.), Social cognitive development (pp. 43-66). Cambridge, England: Cambridge University Press.

Goodall, J. (1970). Tool-using in primates and other vertebrates. In D. S. Leherman, R. A. Hinde, \& E. Shaw (Eds.), Advances in the study of behavior Vol. 3. (pp. 195-249). New York: Academic Press.

Gouzoules, H. (1975). Maternal rank and early social interactions of infant stumptail macaques, Macaca arctoides. Primates, 16, $405-418$.

Gouzoules, H., \& Gouzoules, S. (1989). Design features and developmental modification of pigtail macaque, Macaca nemestrina, agonistic screams. Animal Behaviour, 37, 383-401.

Gouzoules, S., Gouzoules, H., \& Marler, P. (1984). Rhesus monkey (Macaca mulatta) screams: Representational signalling in the recruitment of agonistic aid. Animal Behaviour, 32, 182-193.

Hamilton, W. J., \& Bulger, J. (1992). Facultative expression of behavioral differences between one-male and multimale savanna baboon groups. American Journal of Primatology, 28, 61-71.

Hansen, E. W. (1976). Selective responding by recently separated juvenile rhesus monkeys to the calls of their mothers. Developmental Psychobiology, 9, 83-88.

Hauser, M. D. (1986). Male responsiveness to infant distress calls in free-ranging vervet monkeys. Behavioral Ecology \& Sociobiology, 19, 65-71.

Hausfater, G., Altmann, J., \& Altmann, S. (1982). Long-term consistency of dominance relations in baboons. Science, 217 , $752-755$.

Hume, D. (1977). A treatise of human nature. New York: Dutton, (Original work published 1739).

Humphrey, N. K. (1976). The social function of intellect. In P. P. G. Bateson \& R. A. Hinde (Eds.), Growing points in ethology (pp. 303-317). Cambridge, England: Cambridge University Press.

Jolly, A. (1966). Lemur social behavior and primate intelligence. Science, 153, 501-506.

Kaplan, J. N., Winship-Ball, A., \& Sim, L. (1978). Maternal discrimination of infant vocalizations in the squirrel monkey. Primates, 19, 187-193.

Keil, F. C. (1990). Constraints on constraints: Surveying the epigenetic landscape. Cognitive Science, 14, 135-168.

Keil, F. C. (1991). The emergence of theoretical beliefs as constraints on concepts. In S. Carey \& R. Gelman (Eds.), The epigenesis of mind: Essays on biology and cognition (pp. 237256). Hillsdale, NJ: Erlbaum.

Kohler, W. (1927/1959). The mentality of apes. (E. Winter, Trans). New York: Viking. (Original work published 1927).

Leslie, A. M. (1984). Spatiotemporal continuity and the perception of causality in infants. Perception, 13, 287-305.

Leslie, A. M., \& Keeble, S. (1987). Do six-month-old infants perceive causality? Cognition, 25, 265-288.

Macintosh, N. J. (1974). The psychology of animal learning. London: Academic Press.

Michotte, A. (1963). The perception of causality (T. R. Miles, Trans). New York: Basic Books. (Original work published 1946).

Mitani, J. (1985). Responses of gibbons (Hylobates muelleri) to self, neighbor, and stranger duets. International Journal of Primatology, 6, 193-200.

Palombit R. (1995). The function of 'friendships' between male and female baboons. Manuscript in preparation.

Perner, J. (1991). Understanding the representational mind. Cambridge, MA: MIT Press.

Perrett, D., Harries, M., Mistlin, A. J., \& Chitty, A. J. (1990). Three 
stages in the classification of body movements by visual neurons. In H. Barlow, C. Blakemore, \& M. Weston-Smith (Eds.), Images and understanding: Thoughts about images, ideas about understanding (pp. 94-107). Cambridge, England: Cambridge University Press.

Povinelli, D. J., Nelson, K. E., \& Boysen, S. T. (1990). Inferences about guessing and knowing by chimpanzees (Pan troglodytes). Journal of Comparative Psychology, 104, 203-210.

Premack, D. (1976). Intelligence in ape and man. HIllsdale, NJ: Erlbaum.

Premack, D., \& Premack, A. J. (1994). Levels of causal understanding in chimpanzees and children. Cognition, 50, 347-362.

Premack, D., \& Woodruff, G. (1978). Does the chimpanzee have a theory of mind? Behavioral and Brain Sciences, I, 515-526.

Rescorla, R. A., \& Wagner, A. R. (1972). A theory of Pavlovian conditioning. Variations in the effectiveness of reinforcement and nonreinforcement. In A. Black \& W. Prokasy (Eds.), Classical conditioning II: Current research and theory (pp. 64-69). New York: Appleton-Century-Crofts.

Robinson, J. G. (1981). Vocal regulation of inter- and intragroup spacing during boundary encounters in the titi monkey, Calicebus moloch. Primates, 22, 161-172.

Rumbaugh, D. M., Richardson, W. K., Washburn, D. A., \& Savage-Rumbaugh, E. S. (1989). Rhesus monkeys (Macaca mulatta), video tasks, and implications for stimulus-response spatial contiguity. Journal of Comparative Psychology, 103, 32-38.

Scott, L. M. (1984). Reproductive behavior of adolescent female baboons (Papio anubis) in Kenya. In M. Small (Ed.), Female primates (pp. 77-100). New York: Alan Liss.

Seyfarth, R. M. (1976). Social relationships among adult female baboons. Animal Behaviour, 24, 917-938.

Seyfarth, R. M. (1980). The distribution of grooming and related behaviours among adult female vervet monkeys. Animal Behaviour, 28, 798-813.

Seyfarth, R. M., \& Cheney, D. L. (1990). The assessment of vervet monkeys of their own and another species' alarm calls. Animal Behaviour, 40, 754-764.

Seyfarth, R. M., Cheney, D. L., \& Marler, P. (1980). Vervet monkey alarm calls: Semantic communication in a free-ranging primate. Animal Behaviour, 28, 1070-1094.
Smuts, B., \& Nicolson, N. (1989). Reproduction in wild female baboons. American Journal of Primatology, 19, 229-246.

Spelke, E. S. (1990). Principles of object perception. Cognitive Science, 14, 29-56.

Tokida, E., Tanaka, L., Takefushi, H., \& Hagiwara, T. (1994). Tool-using in Japanese macaques: Use of stones to obtain fruit from a pipe. Animal Behaviour, 47, 1023-1030.

Visalberghi, E. (1992). Is lack of understanding of cause-effect relationships a suitable basis for interpreting monkeys' failures in attribution? Behavioral Brain Sciences, 15, 169-170.

Visalberghi, E., \& Fragaszy, D. (1990). Do monkeys ape? In S. Parker \& K. Gibson (Eds.), Language and intelligence in monkeys and apes: Comparative developmental perspectives (pp. 113-142). Cambridge, England: Cambridge University Press.

Visalberghi, E., \& Limongelli, L. (1994). Lack of comprehension of cause-effect relations in tool-using Capuchin monkeys ( $\mathrm{Ce}$ bus apella). Journal of Comparative Psychology, 108, 15-22.

Visalberghi, E., \& Trinca, L. (1989). Tool use in capuchin monkeys: Distinguishing between performing and understanding. Primates, 30, 511-521.

Waser, P. (1977). Individual recognition, intragroup cohesion, and intergroup spacing: Evidence from sound playback to forest monkeys. Behaviour, 60, 28-74.

Washburn, D. A., Hopkins, W. D., \& Rumbaugh, D. M. (1989). Video-task assessment of learning and memory in macaques (Macaca mulatta): Effects of stimulus movement on performance. Journal of Experimental Psychology: Animal Behavior Processes, 15, 393-400.

Wellman, H. M., \& Gelman, S. A. (1992). Cognitive development: Foundational theories of core domains. Annual Review of Psychology, 43, 337-375.

Whiten, A. (Ed.) (1991). Natural theories of mind: Evolution, development, and simulation of everyday mind-reading. Oxford, England: Basil Blackwell.

Whiten, A., \& Byrne, R. W. (1988). Tactical deception in primates. Behavioral and Brain Sciences, 11, 233-273.

Received March 16, 1994 Revision received October 3, 1994 Accepted October 3, 1994

\section{Mentors for Journal Authors Needed}

APA's Committee on International Relations in Psychology is encouraging publication of international scholars' manuscripts in U.S. journals. To accomplish this initiative, the committee is asking for U.S. "mentors" who are willing to work with non-English-language authors to bring the manuscripts into conformity with English-language and U.S. publication standards. The committee is looking for both translators and those with APA journal experience. Interested individuals should contact

APA International Affairs Office

750 First Street, NE

Washington, DC 20002

Telephone: (202) 336-6025

FAX: (202) 336-5919

Internet: jxb.apa@email.apa.org 